\title{
Utilization of long-acting and permanent contraceptive methods and associated factors among married women in Adama town, Central Ethiopia: community based cross-sectional study
}

\author{
Markos Desalegn ${ }^{1 *}$, Ayele Belachew², Muluken Gizaw², Gemechu Kejela ${ }^{3}$ and Robsan Gudeta ${ }^{3}$
}

\begin{abstract}
Background: Long-acting and permanent contraceptive methods have clear advantages over short-acting methods of contraception that benefit both clients and health systems. Despite this importance, studies show that the proportion of women currently using long acting and permanent contraceptive methods are significantly lower than the proportion using short-acting methods.

Objective: The main aim of the study was to assess the level of utilization of long acting and permanent contraceptive methods and associated factors among married women in Adama town.

Methodology: Community Based Cross-Sectional Study was conducted in four kebeles of Adama town from April 15-30, 2015. Multistage sampling technique was used to select the study participants. The collected data was cleaned and entered using Epi info 3.5.3 and analyzed using statistical package for social science version 20.0. Factors associated with utilization of long acting and permanent contraceptive methods were identified using logistic regression model.
\end{abstract}

Result: In this study, the magnitude of long acting and permanent contraceptive methods was 20.9\%. Implant, Intra-Uterine devices (IUDs) and tubal ligation accounted for 16.1, 4.6, and 0.2\% respectively. Current use of long acting and permanent contraceptive methods was higher among women who had high knowledge (AOR $=5.26$, $95 \% \mathrm{Cl}=1.90-14.69$ ), positive attitude ( $\mathrm{AOR}=3.25,95 \% \mathrm{Cl}=1.60-6.58)$ and women who had 3-4 children (AOR $[95 \% \mathrm{Cl}]=2.3[1.14-4.63])$ compared to those who had no child.

Conclusion: Current use of long acting and permanent contraceptive methods in Adama town was low. Level of knowledge, attitude about the methods, and number of children were factors affecting utilization of long acting and permanent contraceptive methods. Targeted Information Education Communication Intervention should be intensified to improve the utilization of these methods.

Keywords: Utilization, Long acting and permanent, Contraceptive methods

\footnotetext{
* Correspondence: markosdesalegn@gmail.com

'Department of Public health, College of medicine and health sciences,

Jigjiga University, Jigjiga, Somali region, Ethiopia

Full list of author information is available at the end of the article
}

(c) The Author(s). 2019 Open Access This article is distributed under the terms of the Creative Commons Attribution 4.0 International License (http://creativecommons.org/licenses/by/4.0/), which permits unrestricted use, distribution, and reproduction in any medium, provided you give appropriate credit to the original author(s) and the source, provide a link to the Creative Commons license, and indicate if changes were made. The Creative Commons Public Domain Dedication waiver (http://creativecommons.org/publicdomain/zero/1.0/) applies to the data made available in this article, unless otherwise stated. 


\section{Background}

Family planning is a means by which individuals or couples space pregnancy and childbirth at intervals, mutually determined by both husband and wife in order to have the desired number of children [1].

Four contraceptive methods are categorized as LongActing and Permanent Contraceptive Methods (LAPCMs): Intra-Uterine Devices (IUDs), Implants, Tubal ligation, and Vasectomy. IUDs and Implants are long-acting methods; when removed, return to fertility is prompt. Coppercontaining IUDs are effective for 10-12 years. Implants, depending on the type, last for $3-5$ years. Tubal ligation and Vasectomy are permanent methods [2, 3].

LAPCMs have clear advantages over short-acting methods of contraception that benefit both clients and health systems. It increases the contraceptive method options that couples have, especially as their need evolve over time and is the best choice for couples both to space and limit childbirth and is the best way to protect women and couples against unwanted pregnancies [4].

Over time, the use of Long-acting and permanent contraceptive methods has not kept in pace with that of short-acting methods, such as oral contraceptives and injectables [5]. Surveys from four Sub-Saharan countries showed that, the proportion of women currently using LAPCMs is significantly lower than the proportion using short-acting methods, which accounts for less than $5 \%$ [6]. Like other Sub-Saharan countries, Long-Acting and Permanent Contraceptive Methods use have lowest rates in Ethiopia (4.2\%) for which IUD, Implant and Female sterilization contribute $0.3,3.4$ and $0.5 \%$ respectively $[7,8]$.

The growing use of contraception around the world has given couples the ability to choose the number and spacing of their children and has had tremendous lifesaving benefits [9]. Despite this, approximately 25\% of Sub-Saharan African couples and 29\% of Ethiopian couples, who need to space or limit births, are not using any form of modern contraception $[7,8]$.

Therefore, the aim of this study was to assess the utilization of LAPCMs and associated factors among married women.

\section{Methods and materials}

\section{Study area}

The study was conducted in Adama town, located to the east of Addis Ababa at the distance of $99 \mathrm{~km}$. The town has 20 kebeles (the smallest administrative unit in Ethiopia with a geographical boundary of having a minimum of 1000 households). According to the 2007 Census conducted by the Central Statistical Agency of Ethiopia (CSA), the city has a total population of 220, 212. About 60,174 households were counted in the city, which results in an average of 3.66 persons to a household, and 59,431 housing units [10]. Adama town has one government hospital, three private hospitals; six government health centers, one private clinic, one maternal health clinic (Marie Stopes), one Family Guidance Association of Ethiopia (FGAE) and 72 drug shops. From these health institutions, family planning service is being delivered in all hospitals, health centers, FGAE, and Marie Stopes clinics.

\section{Study period}

The study was conducted from April 15-30, 2015.

\section{Study design}

Community-based cross-sectional survey was conducted to assess the utilization of LAPCMs and associated factors among married women aged 15-49 in Adama town.

\section{Source population}

The source populations of the study were all married women aged 15-49 years who live in Adama town during the study period.

\section{Study subject}

The study subject in this study was a sampled married women of age 15-49 years who live in Adama town during the study period.

\section{Sample size determination}

To estimate the sample size, a single population proportion formula with the following assumptions was used.

$$
n=\frac{(Z \alpha / 2)^{2} P(1-(P)}{d^{2}}
$$

\section{Assumptions}

Desired precision $(\mathrm{d})=5 \%$.

Proportion of long acting and permanent contraceptive methods clients from the previous study done in Adigrat and Debre Markos town was $19.5 \%$ each $[11,12]$.

Confidence level $=95 \%$, which means $\alpha$ set at 0.05 and $Z \alpha / 2=1.96$ (value of $Z$ at $\alpha 0.05$ or critical value for normal distribution at $95 \% \mathrm{CI}[13]$.

$$
\begin{aligned}
n & =\frac{(Z \alpha / 2)^{2} P(1-(P)}{d^{2}} \\
n & =\frac{(1.96)^{2} 0.195(1-(0.195)}{(0.05)^{2}} \\
& =241
\end{aligned}
$$

Using a design effect of 2 (since it is a multistage sampling) and a $10 \%$ non-response rate, the calculated minimum sample size was 530 . 


\section{Sampling procedures}

A multi-stage sampling technique was used to select the study participants. The town has 20 kebeles. Out of this, four kebeles were selected using simple random sampling. Then, the number of households with reproductive-age women in each selected kebele were identified and proportionally allocated for the sample size. Sampling fraction was calculated for each kebele and initial household with eligible married women was picked randomly. Finally, study samples were selected using a systematic sampling method. Only one woman was interviewed for households having two or more married women on random to avoid intra-class correlation [13]. In the absence of married women in the sampled household, interviewer jumped to the next house.

\section{Inclusion and exclusion criteria}

Married women of reproductive age group (15-49), women who have lived in the town for more than six months were included. Women having a serious illness and mental disorder were excluded.

\section{Data collection and questionnaire}

A structured interviewer-administered questionnaire was used. The questionnaire was adopted from similar studies done in Mekelle and Adigrat town [11, 13]. It was modified based on the situation of the study to collect information on the utilization of long acting and permanent contraceptive methods and associated factors from married women in Adama town. The questionnaire was prepared in English, translated to Amharic language and translated back to English by another person in order to check its consistency.

The questionnaire has five sections: socio- demography (9 items), reproductive history (6 items), knowledge (18 items), attitude (10 items) and practice of modern contraception (12 items).

The questionnaire was pretested before actual data collection among 28 respondents (5\% of the calculated sample size) in Modjo town. Because population residing in Modjo town share almost similar characteristics with the population in the study area.

Five health extension workers were trained for data collection on the content of the questionnaire and approach to participants during data collection. They were selected based on their ability to speak and write Afan Oromo and Amharic languages.

During data collection, one supervisor was selected to supervise the data collector's activity, checking the completeness of the questionnaire and receive the collected and completed questionnaire. Participants were interviewed, where they were free to express their idea freely. Moreover, on occasions when the sampled women were not be accessed for absence, up to two attempts was endeavored for interviewing to lessen the non-response rate.

\section{Data processing and analysis}

Data were coded, entered into Epi info version 3.5.3 and exported to SPSS version 20.0 for analysis. Descriptive statistics were computed to determine the frequency and percentages. Binary logistic regression was conducted and COR, with $95 \% \mathrm{CI}$ was estimated to select the candidate variables for the final model. Then, variables with a $p$-value of $<0.2$ at binary logistic regression were taken into a multivariable logistic regression to control confounding. Hosmer-Lemeshow goodness-of-fit with stepwise (backward elimination) logistic regression was used to test for model fitness. AOR with 95\% CI was estimated to assess the presence of association at multivariable logistic regression. Finally, variables with a $p$-value of $<0.05$ were considered as statistically significant predictors of the outcome variable.

\section{Operational definition Utilization of LAPCMs}

Is the current use of contraceptive implants or IUDs or Tubal Ligation by the women (study participant) or Vasectomy (male sterilization) by her husband.

\section{User of LAPCMs}

Women who were using either contraceptive implants or IUDs or Tubal Ligation by herself or Vasectomy (male sterilization) by her husband during the data collection period.

\section{Non-user of LACMs}

Were women who were not using contraceptive implants, either IUDs or Tubal Ligation by herself or Vasectomy (male sterilization) by her husband during the data collection period.

\section{Attitude of LAPCMs}

Refers to one's own opinion, belief and perception about LAPCMs. In this study, the attitude of the respondent was measured by attitude statements like using Implant do not lead to abnormal bleeding, Implant and IUD do not move/escape in the body after insertion and using LAPCMs do not lead to abnormal bleeding. It was labeled as a positive and negative attitude where those who have scored above mean of attitude questions was grouped as a positive attitude and mean or below mean was grouped as negative attitude [13].

\section{Knowledge of LAPCMs}

Refers to one's own awareness and familiarity with LAPCMs. Ten knowledge questions were used to grade the knowledge of LAPCMs. It was graded as low knowledge; those who 
have answered less than $60 \%$ of knowledge question; Moderate knowledge; those who have answered $60-79 \%$ of knowledge question; High knowledge: those who have answered above or $80 \%$ of knowledge question [13].

\section{Kebele}

is the smallest administrative unit in Ethiopia with a geographical boundary of having a minimum of 1000 households.

\section{Zone}

Is small administrative subdivision within the kebele.

\section{Data quality management}

To assure the quality of the data, structured intervieweradministered questionnaire was used to collect information. Before the actual data collection, pre-test had been conducted. Data collectors were trained for one day and they have been informed about how to approach the respondents, how to apply the designed data collection method, how to ask each of the questions, follow the instructions of the questionnaire and to keep the confidentiality of the respondents. One supervisor was assigned to check the completeness of the questionnaire every night with the principal investigators.

Table 1 Socio-demographic characteristics of the study

\begin{tabular}{|c|c|c|c|}
\hline S/No & Socio demography & frequency & Percentage \\
\hline \multirow[t]{5}{*}{1} & Age & & \\
\hline & $15-24$ & 128 & 24.3 \\
\hline & $25-34$ & 297 & 56.5 \\
\hline & $35-44$ & 87 & 16.5 \\
\hline & $>45$ & 14 & 2.7 \\
\hline \multirow[t]{5}{*}{2} & Religion & & \\
\hline & Orthodox & 297 & 56.5 \\
\hline & Muslim & 130 & 24.7 \\
\hline & Protestant & 99 & 16.9 \\
\hline & Others* & 10 & 1.9 \\
\hline \multirow[t]{7}{*}{3} & Educational status & & \\
\hline & No education & 49 & 9.3 \\
\hline & Only read and write & 30 & 5.7 \\
\hline & Elementary [1-8] & 161 & 30.6 \\
\hline & Secondary $[9,10]$ & 107 & 20.3 \\
\hline & Senior secondary $[11,12]$ & 66 & 12.5 \\
\hline & Diploma and above & 113 & 21.5 \\
\hline \multirow[t]{4}{*}{4} & Family size & & \\
\hline & $2-3$ & 246 & 46.8 \\
\hline & $4-5$ & 213 & 40.5 \\
\hline & $>5$ & 67 & 12.7 \\
\hline
\end{tabular}

Others*: catholic and Adventist
Table 2 Reproductive history of the study participants, Adama town, April 2015

\begin{tabular}{llll}
\hline S/No & Reproductive history & Frequency & Percentage \\
\hline 1 & Ever gave birth $(n=526)$ & & \\
& yes & 435 & 82.7 \\
& No & 91 & 17.3 \\
2 & Number of birth $(n=435)$ & \\
& $1-2$ & 283 & 65.1 \\
& $3-4$ & 117 & 26.9 \\
& $>4$ & 35 & 8 \\
3 & Number of living children $(n=435)$ & \\
& 0 & 2 & 0.5 \\
& $1-2$ & 293 & 67.4 \\
& $3-4$ & 110 & 25.3 \\
& $>4$ & 30 & 6.9 \\
4 & An additional number of the child they need $(n=435)$ \\
& 0 & 151 & 34.7 \\
& $1-2$ & 236 & 54.3 \\
& $>2$ & 48 & 11 \\
5 & Discussion about modern contraception $(\mathrm{n}=526)$ \\
& Yes & 474 & 90.1 \\
& No & 52 & 9.9 \\
& & &
\end{tabular}

Table 3 knowledge of modern contraceptive methods among study participants

\begin{tabular}{llcc}
\hline S/No & Variables & Frequency & Percentage \\
\hline 1 & Ever heard of modern contraceptive method $(\mathrm{n}=526)$ \\
& Yes & 512 & 97.3 \\
& No & 14 & 2.7 \\
& Type of contraceptive method known $(n=512)$ & \\
Pill & 479 & 93.6 \\
& Injectable & 508 & 99.2 \\
Implant & 433 & 84.6 \\
& IUD & 130 & 25.4 \\
& Tubal ligation & 76 & 14.8 \\
& Vasectomy & 368 & 71.9 \\
& Condom & 388 & 71.9 \\
Source of information( $\mathrm{n}=512)$ & & \\
& Friend, neighbor, and relatives & 137 & 26.8 \\
& Husband & 54 & 10.5 \\
Health professionals & 453 & 88.5 \\
Mass media & 423 & 82.6
\end{tabular}

Each of the percentages does not add up to 100.00 because respondents could choose several responses, which could be spontaneous or prompted 
Table 4 knowledge level of the study participants, Adama town, April 2015

\begin{tabular}{|c|c|c|c|c|c|}
\hline & Knowledge variables $(n=512)$ & knowledge & & & \\
\hline & & True & & False & \\
\hline & & Frequency & percent & frequency & Percent \\
\hline 1 & IUD prevent pregnancy for $>10$ years & 404 & 78.9 & 108 & 21.1 \\
\hline 2 & IUD is not good for women at risk of STI & 246 & 48 & 266 & 52 \\
\hline 3 & IUD has no effect on sexual desire & 349 & 68.2 & 163 & 31.8 \\
\hline 4 & Pregnancy is possible after the removal of IUD & 362 & 70.7 & 150 & 29.3 \\
\hline 5 & Implant prevent pregnancy for $>5$ years & 423 & 82.6 & 89 & 17.4 \\
\hline 6 & Implant has no effect on sexual desire & 409 & 79.9 & 103 & 20.1 \\
\hline 7 & Pregnancy is immediate after removal of the implant & 379 & 74 & 133 & 26 \\
\hline 8 & Vasectomy has no effect on sexual desire & 205 & 40 & 307 & 60 \\
\hline 9 & Pregnancy is not possible after tubal ligation & 312 & 60.9 & 200 & 39.1 \\
\hline
\end{tabular}

\section{Results}

Socio-demographic characteristics of the respondents Five hundred twenty-six married women were interviewed, making response rate of $99.25 \%$. The mean age of the respondents was 29 years $( \pm$ SD 6.31), majority $297(56.5 \%)$ of which belong to the age group of 25-34. Many of the participants were Oromo $220(41.8 \%)$ in ethnicity (data not shown in the table). More than half of the respondents were Orthodox 297 (56.5\%) in religion. Most of the married women interviewed were educated 477(92.2\%), whereas by occupation, $127(51.5 \%)$ of the participants were homemaker. The mean family size of the respondents was 4 $(3.9+\mathrm{SD})$. The majority, $246(46.8 \%)$ of the study respondents have family sizes of $2-3$ (Table 1 ).

\section{Reproductive characteristics of the participants}

About 151 (34.7\%) of the respondents did not need to have more children and 236 (54.3\%) of the participants need to have 1-2 more children. From all participant, 234(44.6\%) want to have a child in the next two years and 292 (55.4\%) did not want to have a child in the next two years (Table 2).

\section{Knowledge of the participants about long acting and permanent contraceptive methods}

From the total respondents, 512(97.3\%) have heard at least one modern contraceptive methods. About 479 (93.6\%), 508 (99.2\%), 433 (84.6\%), 130 (25.4\%) and 76 (14.8\%) of respondents have heard Pill, Injectable, Implant, Tubal ligation and Vasectomy as contraceptive methods respectively. The major source of information was the health profession $453(88.5 \%)$ followed by mass media $423(82.6 \%)$.

Four hundred thirty-five $(87 \%)$ of the respondents knew about long acting and permanent contraceptive methods. Majority of them (66.3\%) knew that IUD prevents pregnancy for more than 10 years. About 69 and $72.1 \%$ knew that pregnancy is possible immediately after removal of IUD and implant respectively. Eighty-seven percent of them had awareness of LAPCMs; $63.7 \%$ as it prevents

Table 5 Attitude of study participants about LAPCMs, Adama town, April 2015

\begin{tabular}{|c|c|c|c|c|c|c|c|}
\hline \multirow[t]{3}{*}{ S/No } & \multirow[t]{3}{*}{ Perception statement $(n=525)$} & \multicolumn{6}{|c|}{ Level of agreement } \\
\hline & & \multicolumn{2}{|l|}{ Agree } & \multicolumn{2}{|l|}{ Not sure } & \multicolumn{2}{|l|}{ Disagree } \\
\hline & & frequency & Percent & frequency & percent & frequency & percent \\
\hline 1 & Implant do not lead to bleeding & 137 & 26.1 & 162 & 30.9 & 226 & 43 \\
\hline 2 & Insertion of IUD does not lead to loss of privacy & 212 & 40.4 & 172 & 32.8 & 141 & 26.8 \\
\hline 3 & IUD does not move through the body & 85 & 16.2 & 163 & 31 & 277 & 52.8 \\
\hline 4 & IUD do not prevent ordinary activity & 93 & 17.7 & 134 & 25.5 & 298 & 56.8 \\
\hline 5 & IUD do not lead to excessive bleeding $(n=524)$ & 93 & 17.7 & 183 & 35 & 248 & 47.3 \\
\hline 6 & Operation of Tubal ligation is not dangerous & 50 & 9.5 & 307 & 58.5 & 168 & 32 \\
\hline 7 & Insertion and removal of implant is painful & 52 & 9.9 & 165 & 31.4 & 308 & 58.7 \\
\hline 8 & Implant do not move through the body & 67 & 12.8 & 127 & 24.2 & 331 & 63 \\
\hline 9 & spouse cannot decide on wife's FPM choice & 253 & 48.2 & 36 & 6.8 & 236 & 45 \\
\hline 10 & HP cannot decide on method choice of FP. & 142 & 27 & 19 & 3.7 & 364 & 69.3 \\
\hline
\end{tabular}


Table 6 Utilization, the reason for not using and service center of modern contraceptive methods of the study participants, Adama town, April 2015

\begin{tabular}{llll}
\hline S/No & Variables & Frequency & Percentage \\
\hline 1 & Current use of methods $(n=315)$ & \\
pill & 41 & 7.8 \\
Injectables & 159 & 30.1 \\
Implant & 85 & 16.1 \\
IUD & 24 & 4.6 \\
Tubal ligation & 1 & 0.2 \\
Condom & 5 & 1 \\
Service center $(n=315)$ & \\
Health center & 165 & 52.4 \\
& Hospitals & 51 & 16.2 \\
Private clinic & 60 & 19.0 \\
Pharmacy & 4 & 1.3 \\
HEW & 3 & 1.0 \\
Relatives & 1 & 0.3 \\
Others**** & 31 & 9.8
\end{tabular}

Others ${ }^{* * * *}$ : Mariestops and FGAE

possible child and maternal death; $69.5 \%$ as it spaces childbirth and $91 \%$ as it limits the family size. Concerning the level of knowledge, $46.8 \%$ of the participant had high knowledge, $24.5 \%$ had moderate knowledge and $28.7 \%$ had low knowledge (Tables 3 and 4).

The attitude of participants about long acting and permanent contraceptive methods

Only 137 (26\%) of the participant agreed that Implant does not bring about excessive bleeding. Three hundred thirteen (59.6\%) of them perceived that insertion of IUD exposes once own privacy and $432(82.3 \%)$ perceived that IUD block ordinary activities. Four hundred fifty-eight $(87 \%)$ of the participants perceived that Implant moves and escapes in the body while most of them perceive that insertion and removal of the Implant is pain full. Concerning the respondent's general attitude status, $55.1 \%$ of the participant had a positive attitude towards LAPCMs while the rest $44.9 \%$ had a negative attitude (Table 5).

\section{Utilization of long-acting and permanent contraceptive methods among respondents Ever use of modern contraceptive methods}

The ever use of the modern contraceptive methods in this study area was $87.1 \%$. The most ever used method was Injectable (66.3\%).

\section{Current use of modern contraceptive methods}

Current modern contraceptive use was $59.8 \%$. The most preferred method was Injectable $159(30.1 \%)$ and Implants $85(16.1 \%)$. The rest were using Pill 41(7.8\%), IUD 24(4.6\%), Condom 5(1\%) and Tubal ligation $1(0.2 \%)$.

\section{None use of modern contraceptive methods and the reasons for nonuse}

About $40.2 \%$ of the respondents were not using any modern contraceptive methods (Table 6). Sixty-three point $5 \%(63.5 \%)$ of them reported that they were not using modern contraceptive methods because of fear side effects (Fig. 1).

The overall prevalence of the LAPCMs was 20.9\%. Majority of them use Implant (16.1\%) and IUD (4.6\%). The rest $0.2 \%$ use tubal ligation. Health center was where majority of the users get the service (52.4\%) while others get service from other government organization (16.2\%) and private clinic (19\%).

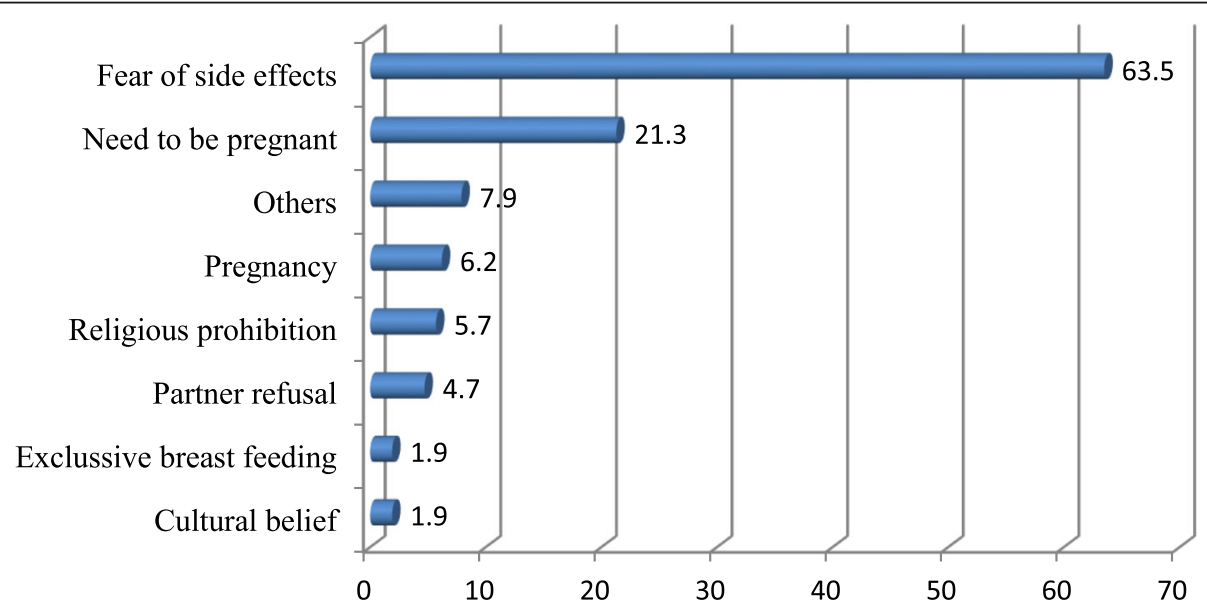

Fig. 1 Reason for not using modern contraceptive method among study participants, Adama tow, April 2015 


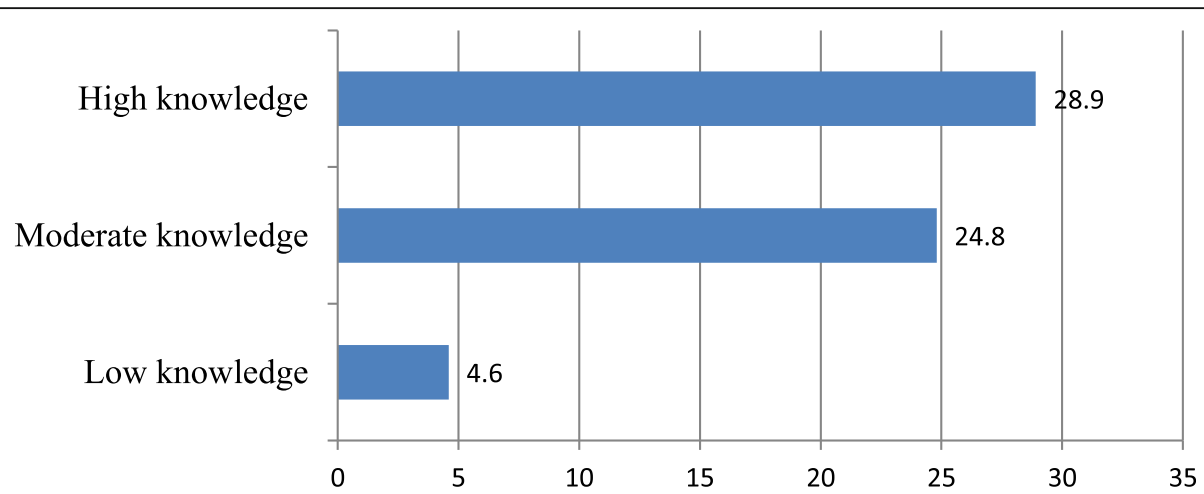

Fig. 2 Current use of LAPCMs by knowledge level of the study participants, Adama town, April 2015

Utilization of LAPCMs among married women who had no formal education was 2 and 28.3\% among diploma and above. Current use of LAPCMs was $4.4 \%$ among married women who did not give birth. However, 37.6 and $25.7 \%$ of married women who gave birth to $3-4$ and $>4$ children were using LAPCMs respectively.

Current use of LAPCMs among those with low knowledge and negative attitude was, 4.6 and $6.8 \%$ respectively. However, current use among those with high knowledge and positive attitude was 28.9 and $32.4 \%$ respectively (Figs. 2 and 3 ).

\section{Factors associated with utilization of long-acting and permanent contraceptive methods}

The result of multivariate analysis revealed that knowledge level was one of the predictors of the current use of LAPCMs. Married women with high knowledge use LAPCMs 5 times more likely than those with low knowledge (AOR $[95 \% \mathrm{CI}]=5.26[1.90-14.69]$ ), and those with moderate knowledge use 3 times more likely compared to those with low knowledge (AOR $[95 \% \mathrm{CI}]=3.27[1.12-$ 9.52]). The attitude of the respondent was also known to predict the current use of LAPCMs in which those who had a positive attitude about LAPCMs use the methods 3 times more likely compared to those who had a negative attitude (AOR $[95 \% \mathrm{CI}]=3.25[1.60-6.58]$ ). In this model, married women who gave birth to 3-4 children use LAPCMs 2 times more likely compared to those who had given birth to $1-2$ children (AOR $[95 \% \mathrm{CI}]=$ 2.3[1.14-4.63]). Participants who need to have 1-2 more children had $67 \%$ lesser odds of using LAPCMs compared to a participant who didn't need any more children (AOR $[95 \% \mathrm{CI}]=0.33[0.16-0.66])$ (Table 7).

\section{Discussions}

The magnitude of the current use of LAPCMs in this study was $20.9 \%$. This result was in line with studies conducted in Adigrat and Debra Markos (19.5\%) each $[11,12]$. The most preferred method was Implant (16.1\%) followed by IUD (4.6\%) and Tubal ligation $(0.2 \%)$. This finding was greater than the study conducted in Nigeria (24.7\%) [14].

In multivariate analysis, knowledge level, attitude status, and a number of children were found to affect the current use of LAPCMs among respondents.

Participants who had high knowledge and moderate knowledge used LAPCMs five and three times more likely compared to the participant of low knowledge. Similarly, a study done in Mekelle revealed, participant of high knowledge had used LAPCMs 8 times more likely compared to low knowledge level. Those who had moderate knowledge used LAPCMs 3 times more likely

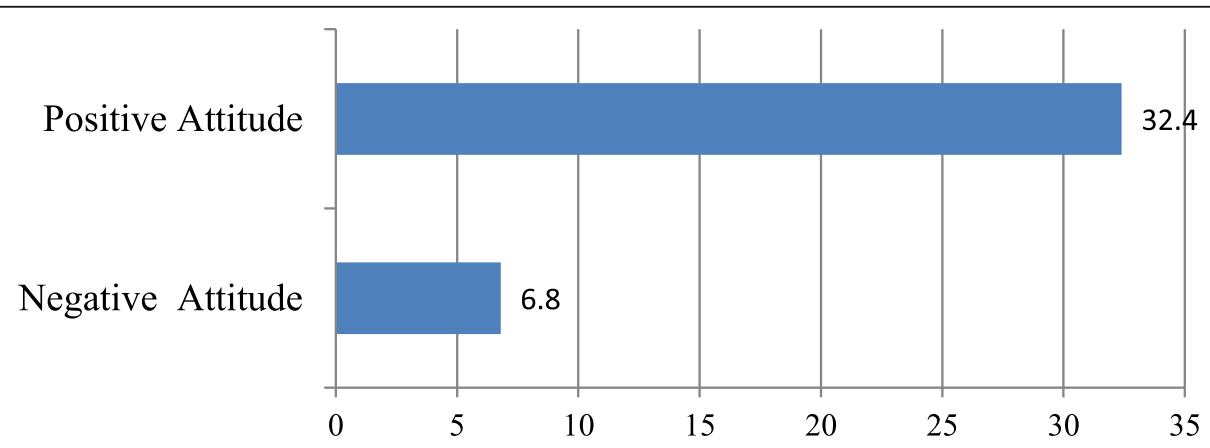

Fig. 3 Current Use of LAPCMs by Attitude status of the study participants, Adama town, April 2015 
Table 7 Multivariate and Bivariate analysis of selected variables affecting utilization of LAPCMs among married women aged 15-49 years, Adama town, April 2015

\begin{tabular}{|c|c|c|c|c|c|}
\hline \multirow[t]{2}{*}{ Variables } & \multirow[t]{2}{*}{ Total } & \multicolumn{4}{|c|}{ Utilization of LAPCMs } \\
\hline & & Yes & No & $\mathrm{COR}_{1}(95 \% \mathrm{Cl})$ & $\mathrm{AOR},(95 \mathrm{Cl})$ \\
\hline \multicolumn{6}{|l|}{ Age of married women } \\
\hline $15-24$ & 66 & $9(13.6)$ & $57(86.4)$ & 1.0(ref) & \\
\hline $25-34$ & 269 & $64(23.8)$ & $205(76.2)$ & $2,(0.93-4.22)$ & $1.43,(0.57-3.60)$ \\
\hline $35-44$ & 87 & $33(37.9)$ & $54(62.1)$ & $3.87,(1.70-8.84)$ & $1.60,(0.51-5.00)$ \\
\hline$>45$ & 13 & $2(15.4)$ & $11(84.6)$ & $1.15,(0.22-6.07)$ & $1.13,(0.14-9.13)$ \\
\hline \multicolumn{6}{|l|}{ Occupation of women } \\
\hline Housewife & 235 & $53(22.6)$ & $182(77.4)$ & 1.0(ref) & \\
\hline Gov't employee & 76 & $26(34.2)$ & $120(78.9)$ & $1.79(1.02-3.14)$ & $0.90,(0.42-1.94)$ \\
\hline Daily labourer & 39 & $4(10.3)$ & $35(89.7)$ & $0.4(0.13-1.15)$ & $0.34,(0.10-1.16)$ \\
\hline Merchant & 53 & $14(26.4)$ & 39 (73.6) & $1.24(0.62-2.44)$ & $0.84(0.36-1.94)$ \\
\hline Student & 18 & $4(22.2)$ & $14(77.8)$ & $0.98(0.3-3.10)$ & $0.76(0.18-3.18)$ \\
\hline NGOS & 14 & $7(50)$ & $7(50)$ & $3.4(1.15-10.2)$ & $4,(1.04-16.20)^{*}$ \\
\hline \multicolumn{6}{|l|}{ No of birth } \\
\hline $1-2$ & 283 & $53(19.4)$ & $230(80.6)$ & 1.0 (ref) & \\
\hline $3-4$ & 117 & $44(37.6)$ & $73(62.4)$ & $2.5,(1.55-4.02)$ & $2.30,(1.14-4.63)^{*}$ \\
\hline$>4$ & 35 & $9(25.7)$ & $26(74.3)$ & $1.44,(0.64-3.24)$ & $1.43,(0.35-5.92)$ \\
\hline \multicolumn{6}{|l|}{ Knowledge level } \\
\hline Low knowledge & 123 & $7(5.7)$ & $144(94.3)$ & 1.0 (ref) & \\
\hline High knowledge & 202 & $69(34.2)$ & $133(65.8)$ & $8.6(3.8-19.45)$ & $5.26(1.9-14.6)^{*}$ \\
\hline Moderate knowledge & 110 & $32(29.1)$ & $78(70.9)$ & $6.8(2.86-16.17)$ & $3.27\left(1.12-9.52^{*}\right.$ \\
\hline \multicolumn{6}{|l|}{ Attitude status } \\
\hline Negative attitude & 187 & $16(8.6)$ & $171(91.4)$ & 1.0(ref) & 1 \\
\hline Positive attitude & 248 & $92(37.1)$ & $156(62.9)$ & $6.3(3.55-11.18)$ & $3.25(1.60-6.58)^{*}$ \\
\hline \multicolumn{6}{|c|}{ Number of the child they wanted } \\
\hline 0 & 151 & $59(39.1)$ & $92(60.9)$ & 1.0(ref) & 1 \\
\hline $1-2$ & 236 & $40(16.9)$ & $196(83.1)$ & $0.32(0.20-0.50)$ & $0.33(0.16-0.66)^{*}$ \\
\hline$>2$ & 48 & $9(18.8)$ & $39(81.2)$ & $0.36(0.16-0.80)$ & $0.5(0.17-1.48)$ \\
\hline
\end{tabular}

*Respective variables are statistically significant

compared to the participant of low knowledge [13]. In addition, finding in Uganda revealed, knowing the duration of protection of IUD and Implant was positively associated with the use of LAPCMs [15]. EDHS 2011 showed, even knowing at least one contraceptive method was prerequisite for use of a contraceptive method [8]. This might be due to the knowledge of contraceptive method helps women to know what and where to use and get the method.

Current use of LAPCMs was higher among participants who had a positive attitude about LAPCMs than those who had a negative attitude. This finding was similar to other findings in Ethiopia where women with positive perceptions about contraceptive methods used contraceptive methods more likely $[16,17]$. In Malaysia practice of LAPMs was surrounded by fear and misperception about a modern contraceptive method like IUD that it had to harmful effects on the health [18]. This might be due to, having a positive attitude was prerequisite for using contraceptive method $[8,17]$.

Participants who gave birth to 3-4 children used LAPCMs more likely than participants who did not give birth. This finding was almost in line with finding in Mekelle where mothers who had more than two pregnancy use LAPCMs three times more likely than mothers who didn't experience any pregnancy [13]. This might be due to fear of infertility after removal of LAPCMs. Participants who need to have more children $[1,2]$ had $67 \%$ lesser odds of using LAPCMs. This might be due to a significant amount of the respondents in this study did not know that pregnancy is immediate after removal of IUD (31.2\%) and Implants (27.9\%). 


\section{Conclusion and recommendation}

The study showed that the utilization of LAPCMs is low despite several efforts made by the federal ministry of health and other stakeholders to escalate it. The main reason for not using the method was the fear of side effects. Knowledge level, attitude status, and parity were found to be associated with utilization of LAPCMs. Information education communication should be intensified and further research should be conducted to explore for other factors associated with utilization of LAPCMs.

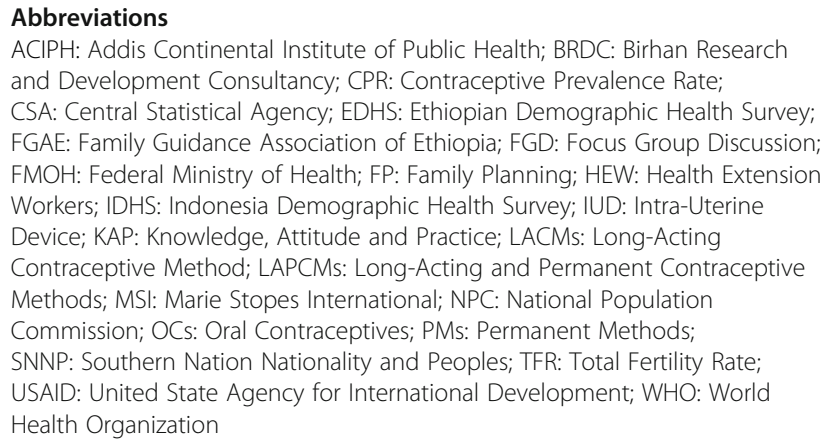

\section{Acknowledgments}

The authors acknowledged Addis Ababa University, school of public health and their library for their support. In addition, the authors would like to thank the study participants, data collectors, and supervisors.

\section{Availability of the data and materials}

The corresponding author can make the required data and material whenever needed.

\section{Authors' contribution}

MD involved in the proposal development, analysis and interpretation of the data and prepared the manuscript. $A B$ and $M G$ involved in conceptualization of the study and analysis of the data. RG and GK involved in the preparation of the manuscript and reviewing the paper. All authors read and approved the final manuscript.

\section{Funding}

Not applicable.

\section{Ethics approval and consent to participate}

Ethical clearance was obtained from Addis Ababa University, School of Public Health Ethical Review committee. Permission for conducting the study was secured from the Oromia Regional Health bureau. Then the official letter was written to Adama Health Bureau. Written consent was obtained from all the study participants after they had briefed about the objectives and the aim of the research. Confidentiality of the information gathered was assured to the interviewee.

\section{Consent for publication}

Not applicable.

\section{Competing interests}

The authors declare that they have no conflicts of interest regarding the publication of the paper.

\section{Author details}

${ }^{1}$ Department of Public health, College of medicine and health sciences, Jigjiga University, Jigjiga, Somali region, Ethiopia. ${ }^{2}$ School of public health, college of health sciences, Addis Ababa University, Addis Abeba, Ethiopia. ${ }^{3}$ Department of public health, Institute of health sciences, Wollega University, Oromia region, Nekemte, Ethiopia.
Received: 15 February 2019 Accepted: 22 October 2019

Published online: 09 December 2019

\section{References}

1. Mayhew S, Osei I, Bajos N. Provider Attitudes to Emergency Contraception in Ghana and Burkina Faso. Population (English Edition). 2013;68(1):115-39.

2. Bureau. PR. By contrast, more than seven of every 10 women in Northern and Western Europe use modern contraception Washington, DC: World Population Data Sheet. 2006.

3. USAID. Long-Acting and Permanent Methods of Contraception: Meeting Clients' Needs: United State International Agency for Development At http:/MWW.poptechproject.com/pathfainder, 2006.

4. World Health Organization. Reproductive H. Medical eligibility criteria for contraceptive use: World Health Organization, 2015.

5. Pile JM, Ndede F, Ndong I, Jacobstein R, Johri N. Investing in the future-the case for long-acting and permanent contraception in sub-Saharan Africa. Arusha, Tanzania: Paper submitted to the Union for African Population ConferenceDecember 2007.

6. Trussell J, Guthrie K. Choosing a contraceptive: efficacy, safety, and personal considerations. Hatcher RA, Trussell J, Nelson AL, Cates W, Stewart FH, Kowal D Contraceptive technology 19th revised ed New York (NY): Ardent Media, Inc2007:19-47.

7. Dr. Zaheen B DJH, Dr. Sarah S. Factors affecting hormonal and nonhormonal contraceptive method use in women presenting to Reproductive Health.IOSR Journal of Dental and Medical Sciences (JDMS)SepOct. 2012:volume 2(Issue1).

8. CSA [Ethiopia], ICF [International]. Ethiopia Demographic and Health Survey 2011. Addis Ababa, Ethiopia, and Calverton, Maryland, USA: Central Statistical Agency and ICF International, 2012.

9. Darroch JE, Singh S. Trends in contraceptive need and use in developing countries in 2003, 2008, and 2012: an analysis of national surveys. Lancet; 381(9879):1756-62.

10. Ethiopia CSA. National population and housing census. Addis Addis Ababa2007

11. Gebremariam A, Addissie A. Intention to use long acting and permanent contraceptive methods and factors affecting it among married women in Adigrat town, Tigray, northern Ethiopia. Reprod Health. 2014;11(1):24.

12. Bulto GA, Zewdie TA, Beyen TK. Demand for long acting and permanent contraceptive methods and associated factors among married women of the reproductive age group in Debre Markos town, north West Ethiopia. BMC Womens Health. 2014;14(1):46.

13. Alemayehu M, Belachew T, Tilahun T. Factors associated with the utilization of long acting and permanent contraceptive methods among married women of reproductive age in Mekelle town, Tigray region, North Ethiopia. BMC pregnancy and childbirth. 2012;12(1):6

14. Eko Jimmy E, Osonwa Kalu O, Osuchukwu Nelson C, Offiong Dominic A. Prevalence of Contraceptive use among women of reproductive age in Calabar Metropolis, Southern Nigeria. International Journal of Humanities and Social Science Invention ISSN (Online): 2319-7722, ISSN (Print): 2319-7714 www.ijhssi.org Volume 2 Issue 6 II June. 2013|l PP.27-34.

15. Anguzu, al.: e. Knowledge and attitudes towards the use of long acting reversible contraceptives among women of reproductive age in Lubaga division, Kampala district, Uganda. BMC Research Notes2014;7:153.

16. Lee $\mathrm{T}$, Lee $\mathrm{H}$, Ahn HM, Jang $Y$, Shin H, Kim MS. Perceptions about family planning and contraceptive practice in a marital dyad. J Clinical Nursing. 2014;23(7-8):1086-94. https://doi.org/10.1111/jocn.12348 Epub 2013 Sep 6.

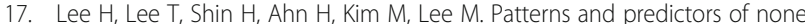
use of family planning methods in Ethiopian women: a panel survey. Int Nurs Rev. 2013:60(3):335-43.

18. FSA N, Rahman HA, Juni MH. Barriers to Modern Contraceptive Practices among Selected Married Women in a Public University in Malaysia. Global J Health Sci. 2013;3(2)

\section{Publisher's Note}

Springer Nature remains neutral with regard to jurisdictional claims in published maps and institutional affiliations. 